\title{
NISTIR 90-4239
}

NEW NIST PUBLICATION

July 1990

\section{STUDIES ON THE}

MELT FLOW RATE OF

THE SRM 1474,

A POLYETHYLENE

RESIN

\section{John R. Maurey \\ Charles M. Guttman}

U.S. DEPARTMENT OF COMMERCE

Natlonal Institute of Standards

and Tochnology

Instltute for Materlals Sclence

and Englneering

Polymers Division

Galthersburg, MD 20899

Report to OSRM

U.S. DEPARTMENT OF COMMERCE Robert A. Mosbacher, Secretary NATIONAL INSTITUTE OF STANDARDS AND TECHNOLOGY

John W. Lyons, Director

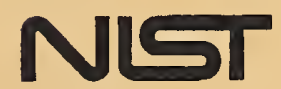





\section{STUDIES ON THE}

MELT FLOW RATE OF

THE SRM 1474,

A POLYETHYLENE

RESIN

\section{John R. Maurey \\ Charles M. Guttman}

U.S. DEPARTMENT OF COMMERCE

Natlonal Instltute of Standards

and Technology

Institute for Materlals Sclence

and Englnooring

Polymers Dlvlslon

Galthersburg, MD 20899

Report to OSRM

January 1989

lesued March 1990

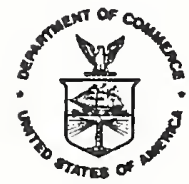

U.S. DEPARTMENT OF COMMERCE Robert A. Mosbacher, Secretary NATIONAL INSTITUTE OF STANDARDS AND TECHNOLOGY

John W. Lyons, DIreetor 

The melt flow rate of SRM 1474, a polyethylene, was determined to be 5.03 $\mathrm{gm} / 10 \mathrm{~min}$ at $190{ }^{\circ} \mathrm{C}$ under a load of $2.16 \mathrm{~kg}$ using the ASTM method D1238-86. The average results from 30 determinations on samples with a standard deviation of a single measurement of $0.037 \mathrm{gm} / 10 \mathrm{~min}$. A small but measurable drift from the first timed extrudate to the third timed extrudate was observed. 



\section{Introduction}

Melt flow rate is widely used in polymer technology as a product specification since this value, which includes a statement of the load and temperature under which it is obtained, gives an indication of the processing properties of the polymer. The value of melt flow rate is expressed as the mass of polymer melt pushed from the heated cylinder of the extrusion plastometer through its precision bore orifice by its piston in a period of time, the standard units of the value being grams per ten minutes ( $\mathrm{g} / 10 \mathrm{~min})$.

In this paper, we report the determination of melt flow rate of a polyethylene resin. This is a report on the melt index certification.

\section{Experimental Procedure}

\subsection{Sampling and Randomization of Charge Sequence of SRM 1474}

Bulk material for the SRM 1474 came in one 50 pound bag of pellets. The Office of Standard Reference Materials (OSRM) blended the material and divided the bag into 379 units of 60 grams each. Ten of these units were chosen randomly for homogeneity and certification studies. In preparation for the melt flow rate experiments, three charges were taken from each of the randomly chosen units. Charges to be extruded were identified by an ordinal number, each associated with an identified sample. The sequence of charges to be extruded was randomized according to a procedure described by Natrella ${ }^{1}$, and applying the Rand tables ${ }^{2}$.

\subsection{Instrument Calibration and Alignment}

\subsubsection{Temperature Indication}

The temperature was indicated by a mercury column thermometer of the form described in paragraph 4.7 of the ASTM D1238-86 method. Calibration of the temperature indication is traceable to the NIST Temperature and Pressure Division. An iron-contantan thermocouple was calibrated by correlating its emf with the scale readings of an ASTM $68 \mathrm{C}$ thermometer at 22 points from $183^{\circ} \mathrm{C}$ to $195^{\circ} \mathrm{C}$, in a constant temperature oil bath. The ASTM 68C thermometer had been calibrated at the ice point and at $190^{\circ} \mathrm{C}$ in the NIST Temperature and Pressure Divison. The cylinder thermometer in the extrusion plastometer was calibrated by correlating its scale readings with the temperature indicated by the emf from the thermocouple with its hot junction stationed in a column of polythylene melt in the bore, as described in paragraph 4.5 .2 of the ASTM method. Thermal conductivity between cylinder and thermometer, and between cylinder and the temperature control sensing probe, was enhanced by adding silicone oil to the wells in the cylinder for the thermometer and sensing probe. p. $1-6$.

1 M. G. Natrella: "Experimental Statistics," NBS Handbook 91, Section 1-4,

2 The Rand Corp.: "A Million Random Digits with 100,000 Normal Deviates", The Free Press, N.Y. (1955). 
The uncertainty in the final temperature indication may be regarded as equal to the nominal limit of resolution on the scales of the ASTM 68C thermometer, and of the thermometer in the extrusion plastometer, $0.1^{\circ} \mathrm{C}$. A determination of melt flow rate dependence on temperature, for SRM 1496 , resulted in a change of $0.00043 \mathrm{~g}$ per $10 \mathrm{~min}$ in melt flow rate for a $0.1{ }^{\circ} \mathrm{C}$ change in temperature under the $2.16 \mathrm{~kg}$ load. This result affords an estimate of $0.17 \%$ change in melt index per $0.1^{\circ} \mathrm{C}$ change in temperature.

\subsubsection{Metering of Plastometer Components}

The geometric dimensions of the new cylinder, piston assemblies, and dies were found to comply with the specifications described in the ASTM method.

The diameter of the cylinder bore was determined by a Brown and Sharpe model 599-281 Intrimik inner diameter (ID) micrometer. ${ }^{3}$ The ID of the bore was measured at the bottom end (micrometer head resting on a die at the bottom), and at levels from $15 \mathrm{~cm}$ down from the top end, up to $2 \mathrm{~cm}$ from the top end, in $1 \mathrm{~cm}$ intervals. All of the resulting measurements were either $0.9543 \mathrm{~cm}$ (0.3757 in.), $0.9545 \mathrm{~cm}(0.3758$ in.), or $0.9548 \mathrm{~cm}(0.3759$ in.) in compliance with the tolerance of this specification described in paragraph 4.2 of the ASTM method.

The apparent mass of the nominal $2.16 \mathrm{~kg}$ load was determined in the NIST Length and Mass Division. The apparent mass of the nominal $2.16 \mathrm{~kg}$ load was found to be $2.1599 \mathrm{~kg}$, well within the \pm 0.58 tolerance described in paragraph 4.4.4 of the ASTM method.

\subsubsection{Alignment of Plastometer}

The cylindrical axis of the bore was aligned with the gravity vector by the following plumb-line procedure.

First, a die was selected as the "target" die and stationed on the structural baseplate of the extrusion plastometer directly below the cylinder. Its position on the plane of the baseplate was adjusted to have the axis of its orifice coincide with the projection from the axis of the cylinder bore onto that plane. This was accomplished by viewing the target die through the orifices of two "sighting" dies, one stationed at its operational position in the bottom end of the bore and the other stationed at the top end of the bore. The position of the target die on the plane of the baseplate was adjusted until it appeared centered in the view from above the cylinder through the sighting dies in the bore.

Next a plumb-bob was suspended by a plumb-line from the axis of a die supported in the top end of the bore, with the bob almost touching the top surface of the target die. The leveling screws were adjusted until the pointer of the plumb-bob appeared to be centered above the orifice of the target die.

${ }^{3}$ Certain commerical materials and equipment are identified in this paper in order to specify adequately the experimental procedure. In no case does such identification imply recommendation or endorsement by the National Institute of Standards and Technology, nor does it imply necessarily the best available for the purpose 


\subsection{Melt Flow Rate on SRM 1474}

The melt flow rates on SRM 1474 were determined by procedure A described in Section 8 of ASTM Method D-1238-84. Standard test condition 190/2.16 was used. Thus the flow rate was determined at $190.0 \pm 0.1^{\circ} \mathrm{C}$ using a load of $2.16 \mathrm{~kg}$. The flow rate of the melt was measured by a manually operated extrusion plastometer obtained from the Tinius Olsen Testing Machine Co. ${ }^{3}$

A $5.5 \mathrm{~g}$ charge of pellets was used for extrusions under the $2.16 \mathrm{~kg}$ load. With such a charge the $4 \mathrm{~mm}$ start section of the descending piston would partially enter the top of the guide collar at the end of the 6 min preheat interval without the necessity of any manipulative adjustment. The end of the 6 min preheat interval was marked as the beginning of timed extrusion by making the initial extrudate cut and discarding this preheat segment. Three timed extrudate segments were cut at one min intervals thereafter. After the third timed extrudate segment had been cut the remaining melt in the cylinder was purged and discarded. The piston, bore, and die were cleaned free of the polymer at the end of each extrusion.

\section{Data Analysis}

\subsection{Data Analysis on the Melt Flow Rate of SRM 1474 Resin}

Data from 30 charges were analyzed for the $2.16 \mathrm{~kg}$ load. The data from a single charge run generally showed a very slight flow rate increase as one went from the first timed extrudate to the third timed extrudate. Such a drift is reflected in the data shown in Table 1.

Six melt flow rate experiments could be done in a single day. The plastometer was often shut down for a few days before the next set of significant extrusions were conducted. With this procedure we hoped to show the effects of day to day variability on the equipment and have that reflected in our standard deviation. However in general the day to day variability was small compared to the charge to charge variability.

\subsection{Error Analysis Melt Index}

Obtaining an error analysis of the melt index is a difficult matter since it is not a fundamental property of the material and there is no simple relationship describing its estimation. Nonetheless we shall make an effort in this section to estimate the possible causes of error and their contribution to the overall actual error in the mea.surement made.

\subsubsection{Instrument Variability}

One estimate of error comes from the ASTM method on which melt flow rate is based--ASTM D1238-86. Table 3 of the ASTM method indicates an expected reproducibility for polyethylene of \pm 0.04 for a melt flow of $0.25 \mathrm{~g} / 10 \mathrm{~min}$ and \pm 0.48 for a melt flow of $7.0 \mathrm{~g} / 10 \mathrm{~min}$. (These are 958 confidence limits).

41987 Annual Book of ASTM Standards, Vol. 08.01, pp. 552-565. 
Since this error estimate includes inter-laboratory as well as intralaboratory error one would expect our error to fall within the ASTM prescribed range as it does.

What the ASTM reproducibility described in their table 3 is due to is not clear. As we have pointed out melt flow is not a fundamental physical property. We have seen from our own measurements that its value may depend on where you choose to make the cuts in the material for example (first extrudate or second extrudate). We may then ascribe part if not all of the ASTM error tolerance as described in their table 3 to operator-to-operator variability or to instrument-to-instrument variability which we are unable to estimate on our own. This estimate yields a possible systematic error of about 108 on the flow rate for SRM 1474.

Estimates of our own repeatability are in Table 2. These data reflect the repeatability of our own experiments and do not reflect any instrument-toinstrument or operator-to-operator variation since we had only one of each. We did make our runs on various days and the day-to-day variability was less than the charge to charge variability. The sample to sample variability is also less than the charge to charge variability.

Finally we try to estimate the intrinsic error in the measurement. We do this by considering the errors in the measured quantities (mass and time) as well as the errors in the controlled quantities (temperature and the specifications on the instrument). The melt flow rate, $F$, is given by

$$
\mathrm{F}=\text { Mass } / \text { Time }
$$

Thus any error in the melt flow rate is then

$$
\mathrm{dF} / \mathrm{F}=\mathrm{dm} / \mathrm{m}+\mathrm{dt} / \mathrm{t}+(\mathrm{m} / \mathrm{dT})(\mathrm{dT} / \mathrm{T})
$$

These terms are: $\mathrm{dm} / \mathrm{m}$ is the fractional error in the weight of the samples-this is taken to include the possible error in the weighing due to balance error and moisture pickup but also to mass of the extrudate errors incurred due to the cutting of the material. $d t / t$ is the fractional error in the timing of the extrudate--this is taken to include only the timing error. The $\mathrm{dT} / \mathrm{T}$ term is the term arising from the inaccuracy of the temperature controller as well as temperature inhomogeneity of the melt indexer. The cause of these errors are discussed in the next few paragraphs. These with the other errors are given in table 2 as well as an estimate of the overall error resulting from all sources.

\subsubsection{Weighing Error}

The extrudate segments were weighed on a balance with $0.01 \mathrm{mg}$ resolution in mass indication. Replicate weighing of the segments agreed to within \pm 0.01 $\mathrm{mg}$. in general and never varied beyond $\pm 0.02 \mathrm{mg}$ at the extreme. Paragraph 8.9 of ASTM method D 1238-86 instructs the experimenter to "weigh the extrudate to the nearest $1 \mathrm{mg}$ when cool." It should be noted that $1 \mathrm{mg}$ of this polymer occupies very nearly 1 microliter of volume which is probably a valid estimate of the uncertainty in the cut considering the technique of cutting the extrudate. Consequently, the uncertainty in extrudate mass resulting from the process of cutting the segment is estimated $\mathrm{dm}= \pm 1 \mathrm{mg}$. The overall average apparent mass $m=503 \mathrm{mg}$ for SRM 1474 was calculated for all the extrudate 
segments in the characterization of this polymer. Consequently, the relative error in weight $(\mathrm{dm} / \mathrm{m})$ entering into the melt index characterization is

$$
\mathrm{dm} / \mathrm{m}= \pm 1 \mathrm{mg} / 500 \mathrm{mg}=0.28 \text { for SRM } 1474
$$

The extrudate segments were routinely weighed within one hour after having been cut, in compliance with the instruction in paragraph 8.9 of the ASTM method. Considering the hydrophobic character of polyethylene it would not be anticipated that the extrudate would accumulate moisture beyond the initial cooling stage prior to being weighed. On a few occasions during the characterization of another polyolefin, extrudate segments, which had been weighed at the end of a day, were weighed again on the following day without detecting any statistically valid change of weight within the groups. All individual changes, either positive or negative, were much smaller than $1 \mathrm{mg}$. Consequently, it may be assumed that there was no detectable error in weight attributable to moisture adsorption, and that the error in extrudate weight is overwhelmingly dominated by the volume uncertainty attending the process of cutting the extrudate.

\subsubsection{Timing Error}

The interval ( $t$ ) between extrudate cuts for SRM 1474 was measured with a battery powered stopwatch having a $0.01 \mathrm{sec}$ resolution in time indication. The extrudate cut was timed to better than $0.1 \mathrm{sec}$. Consequently the timing error is $0.1 \mathrm{sec}$. as a practical estimate. Hence, the relative error in time interval may be expressed

$$
\mathrm{d} t / \mathrm{t}= \pm 0.1 \mathrm{sec} / 60 \mathrm{sec} .=0.178
$$

\subsubsection{Temperature Error}

The thermal profile of an undisturbed column of polyethylene melt was scanned along the cylindrical axis of the cylinder bore. This experiment was conducted in another extrusion plastometer during an earlier determination of the melt flow rate of SRM 1475 and SRM 1476. The temperature in the stationary melt column was measured with a thermocouple hot junction stationed at different heights above the top surface of the die, along the cylindrical axis of the bore. Throughout the experiment the indicated cylinder temperature remained at $190.0^{\circ} \mathrm{C}$ in all observations of the mercury column thermometer routinely used to indicate cylinder temperature. The results are listed in Table 3 .

Inspection of the tabulated results indicates that the departure of melt temperature from the indicated cylinder temperature is within $\pm 0.1^{\circ} \mathrm{C}$, at any location in the melt column from $12 \mathrm{~mm}$ above the die upward. It may be observed that the $0.7-0.8^{\circ} \mathrm{C}$ drop in temperature, between the $12 \mathrm{~mm}$ and $1 \mathrm{~mm}$ levels above the die, occurred in the melt column undisturbed. This temperature drop is probably at least partially erased by the downward flow of melt during an extrusion. It is also possible that the apparent smaller variation of temperature with height from $12 \mathrm{~mm}$ upward may be a variation of temperature with time at which the temperature was determined at the different levels. Because of its considerably greater heat capacity and volume displacement, the mercury column thermometer is a very effective temperature averaging device and far less responsive to brief and small changes in 
temperature, in comparison with a very small and intensively responsive thermocouple junction. Regardless of whether the temperature is changing with time or with height, or both height and time, the maximum temperature error (dT) may be estimated as $\pm 0.1^{\circ} \mathrm{C}$.

The greater significance of temperature error is its effect on the melt index of this polymer. The variation of melt flow rate of a similar polyethylene polymer with temperature in the vicinity of $190^{\circ} \mathrm{C}$ was determined to be $1.65 \% /{ }^{\circ} \mathrm{C}$. This is equivalent to $0.17 \% / 0.1{ }^{\circ} \mathrm{C}$ corresponding to the $0.1{ }^{\circ} \mathrm{C}$ maximum error in the melt temperature. 
Table 1

Melt Flow Rate of

SRM 1474 at a Load of $2.16 \mathrm{~kg}$

And a Temperature of $190{ }^{\circ} \mathrm{C}$

$\operatorname{Mean}(a)$

95\% Confidence

Interval of Mean

(a)
Standard

Deviation of

a Single

Measurement

(a)

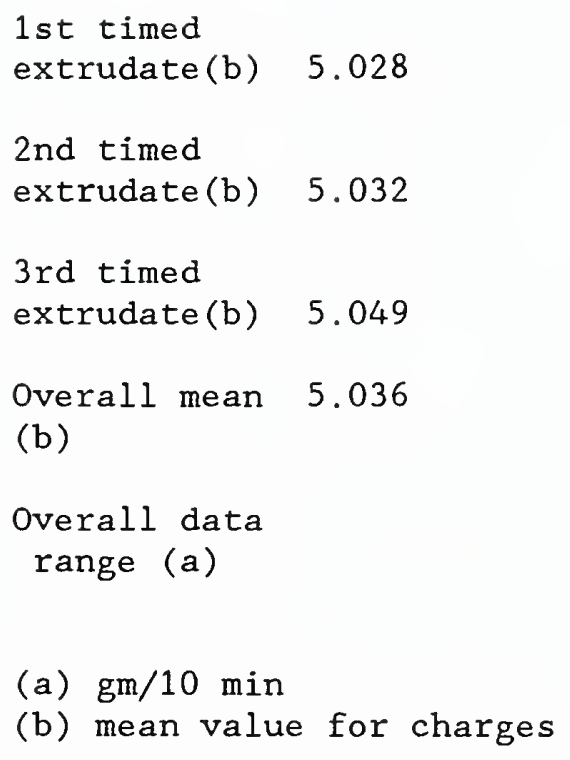

Overall data

range (a)
(a) $\mathrm{gm} / 10 \mathrm{~min}$
(b) mean value for charges

5.029 to 5.044

0.037

4.924 to 5.131 


\section{Table 2}

Estimates of Errors in Melt Flow Rate of SRM 1474 polyethylene under condition 190/2.16

1. Overall estimated repeatability of experiment

0.748

(see Table 1)

2. Instrument Variability

88 as estimated from error reported in ASTM method

3. $d m / m * 100$

0.28

4. $d t / t * 100$

0.178

5. $\mathrm{dT} / \mathrm{T} * \mathrm{dF} / \mathrm{dT}$

0.178

6. Overall estimated error

98 


\section{Table 3}

Variation of Temperature with Height in Undisturbed Melt in Cylinder Bore

$\begin{array}{lc}\text { Height Above } & \text { Melt Temp } \\ \text { Die, mm } & { }^{\circ} \mathrm{C} \\ 48 & 190.09 \\ 36 & 189.93 \\ 24 & 189.97 \\ 12 & 189.94 \\ 1 & 189.23\end{array}$


(DRAFT CERTIFICATE)

Standard Reference Material 1474

Polyethylene Resin

This Standard Reference Material (SRM) is intended for use in calibration and performance evaluation of instruments used in polymer technology and science for the determination of the Melt Flow Rate using ASTM Method D1238-86. The SRM is supplied as white pellets of polyethylene.

This material is certified for Melt Flow Rate using ASTM Method D1238-86 condition 190/2.16. Under this condition the melt flow rate is $5.03 \mathrm{~g} / 10$ minutes with a standard deviation for a single measurement of $0.037 \mathrm{~g} / 10$ minutes and with 29 degrees of freedom.

The technical coordination leading to certification of this material was provided by $F$. W. Wang with technical measurement and data interpretation provided by J. R. Maurey and C. M. Guttman. 


\begin{tabular}{|c|c|c|}
\hline \multirow[t]{4}{*}{$\begin{array}{l}\text { NIST-114A } \\
\text { (REV. 3-89) }\end{array}$} & \multirow{4}{*}{$\begin{array}{l}\text { U.S. DEPARTMENT OF COMMERCE } \\
\text { NATIONAL INSTITUTE OF STANDARDS AND TECHNOLOGY } \\
\text { BIBLIOGRAPHIC DATA SHEET }\end{array}$} & \begin{tabular}{|l} 
1. PUELCATION OR REPORT NUMBER \\
NISTIR $90-4239$
\end{tabular} \\
\hline & & 2. PERFORMING ORGANIZATION REPORT NUMBER \\
\hline & & \\
\hline & & April 1990 \\
\hline
\end{tabular}

4. TITLE AND SUBTITLE

Studies on the Melt Flow Rate of the SRM 1474, A Polyethylene Resin

5. AUTHOR(S)

J. R. Maurey and C. M. Guttman

6. PERFOAMINO ORGANIZATION (IF JOINT OR OTHER THAN NIST, SEE INSTRUCTIONS) U.S. DEPARTMENT OF COMMERCE

NATIONAL INSTITUTE OF STANDARDS AND TECHNOLOGY

GAITHERSBURG, MD 20899

7. CONTRACT/GRANT MUMBER

8. TYPE OF REPORT AND PERIOD COVERED

9. SPONSORING ORGANIZATION NAME AND COMPLETE ADDRESS (STREET, CITY, STATE, ZIP)

10. SUPPLEMENTARY NOTES

DOCUMENT DESCRIBES A COMPUTER PROGRAM; SF-185, FIPS SOFTWARE SUMMAFY, IS ATTACHED.

11. ABSTRACT (A 200-WORD OR LESS FACTUAL SUMMARY OF MOST SIGNIFICANT INFORMATION. IF DOCUMENT INCLUDES A SIGNIFICANT BIBLOORAPHY OR LITERATURE SURVEY, MENTION IT HERE.)

The melt flow rate of SRM 1474, a polyethylene, was determined to be $5.03 \mathrm{gm} / 10 \mathrm{~min}$ at $190^{\circ}$ under a load of $2.16 \mathrm{~kg}$ using the ASTM method D1238-86. The average results from 30 determinations on samples with a standard deviation of a single measurement of $0.037 \mathrm{gm} / 10 \mathrm{~min}$. A small but measurable drift from the first timed extrudate to the third timed extrudate was observed.

12. KEY WORDS (6 TO 12 ENTRIES; ALPHABETICAL ORDER; CAPITALIZE ONLY PROPER NAMES; AND SEPARATE KEY WORDS BY SEMICOLONS)

melt flow rate; melt index, polyethylene; polymer; polymer processing;

Standard Reference Materials

13. AVAILABILITY

$\mathrm{X}$ UNLUMITED

FOR OfFICIAL DISTRIBUTION. DO NOT RELEASE TO NATIONAL TECHNICAL INFORMATION SERVICE (NTIS).

ORDER FROM SUPERINTENDENT OF DOCUMENTS, U.S. GOVERNMENT PRINTINO OFFICE, WASHINGTON, DC 20402.

ORDER FROM NATIONAL TECHNICAL INFORMATION SERVICE (NTIS), SPRINGFIELD, VA 22161.
14. NUMBER OF PRINTED PAGES

14 

